\title{
Estudo da Reação entre Polietileno Glicol e Resina Epoxídica na Presença de N,N-dimetilbenzilamina
}

\author{
Mario Zacharuk, Daniela Becker \\ Centro de Ciências Tecnológicas, UDESC \\ Instituto Superior Tupy, SOCIESC
}

\author{
Luiz A. F. Coelho, Sergio H. Pezzin \\ Centro de Ciências Tecnológicas, UDESC
}

\begin{abstract}
Resumo: Neste trabalho foi estudada a reação entre polietileno glicol (PEG) e uma resina epoxídica à base de diglicidil éter de bisfenol A (DGEBA), na presença de N,N-dimetilbenzilamina (DMBA), sendo os produtos desta reação avaliados por espectroscopia no infravermelho (FTIR), espectroscopia de ressonância magnética nuclear de próton $\left(\mathrm{RMN}-{ }^{1} \mathrm{H}\right)$ e medidas de viscosidade cone-prato. Amostras curadas com um endurecedor à base de poliamina foram também submetidas a ensaios de tração e calorimetria exploratória diferencial (DSC). Os resultados das análises de viscosidade, FTIR e RMN $\left({ }^{1} \mathrm{H}\right)$ confirmaram a ocorrência da reação entre grupos epóxi do DGEBA e grupos hidroxila do PEG na presença de DMBA, a $100{ }^{\circ} \mathrm{C}$. As análises de DSC e os ensaios de tração dos sistemas curados mostram que a reação de DGEBA com PEG gera um material com temperatura de transição vítrea (Tg) significativamente menor, em conjunto com o aumento da deformação na ruptura e decréscimo do modulo de elasticidade, quando comparados ao sistema epoxídico de referência (DGEBA).
\end{abstract}

Palavras-chave: DGEBA, polietileno glicol, DMBA, propriedades mecânicas.

\section{Study of the Reaction Between Polyethylene Glycol and Epoxy Resins Using $\mathrm{N}, \mathrm{N}$-dimethylbenzylamine as Catalyst}

Abstract: In this work the reaction of polyethylene glycol (PEG) and epoxy resin (BADGE) in the presence of N,N-dimethylbenzylamine (DMBA) was studied. The reaction products were evaluated by infrared spectroscopy (FTIR), nuclear magnetic resonance spectroscopy (NMR) and viscosity measurements. Samples cured with a polyamine-based hardener were also submitted to tensile tests and differential scanning calorimetry (DSC). The results of the viscosity analyses, FTIR and RMN $\left({ }^{1} \mathrm{H}\right)$ confirmed the reaction between DGEBA epoxy groups and PEG hydroxyl groups in the presence of DMBA, at $100{ }^{\circ} \mathrm{C}$. DSC analyses and tensile tests of cured systems showed that the reaction of DGEBA with PEG leads to a reduction of $\mathrm{Tg}$, generating a more flexible material.

Keywords: BADGE, polyethylene glycol, DMBA, mechanical properties.

\section{Introdução}

Entre as classes de termorrígidos mais utilizados industrialmente, as resinas epoxídicas apresentam várias características interessantes, como boa aderência e estabilidade dimensional, baixa contração durante a cura, boa resistência mecânica, química e à corrosão, baixo custo e facilidade de processamento, sendo muito usadas em adesivos, laminados e revestimento ${ }^{[1]}$. No entanto, são frágeis após a cura se forem comparadas aos termoplásticos semicristalinos, devido a tensões localizadas que geram microtrincas e podem causar fratura prematura em pequenas deformações ${ }^{[2]}$.

Atualmente, existe uma grande variedade de resinas epoxídicas disponíveis, apresentando diferentes propriedades em função dos tipos de epóxi, agentes de cura, procedimentos de cura e diferentes formulações existentes. Uma outra propriedade importante da resina epoxídica é a viscosidade, que está relacionada com a massa molecular e sua distribuição, presença de solvente e pela maneira que ela foi constituída quimicamente ${ }^{[3]}$.

Em função de apresentar facilidade durante o processamento, baixa contração e boa fluidez, a resina epoxídica mais utilizada em diversas aplicações é o diglicidil éter de bisfenol A (DGEBA), cuja estrutura química é mostrada na Figura 1.
As características da resina epoxídica podem ser modificadas quimicamente para aplicações específicas, por exemplo, para gerar um material de alta tenacidade ${ }^{[4,5]}$. Uma possibilidade para aumentar a flexibilidade destes materiais, proposta neste trabalho, é a reação entre a resina epoxídica e polietileno glicol (PEG). Há também interesse de pesquisadores em estudar o uso de nanotubos de carbono funcionalizados com PEG como reforço em matriz epóxi, assim é necessário verificar como a reação entre grupos epóxi e PEG acontece e quais alterações podem ocorrer nas propriedades após a cura ${ }^{[6,7]}$.

A reação de grupos epoxídicos com grupos hidroxilas de álcoois pode ocorrer por catálise ácida ou básica, requerendo altas temperaturas na ausência de um catalisador ${ }^{[8]}$. A reação entre DGEBA e um diol, com ou sem catalisador, gera álcoois primários e secundários, sendo que a razão entre os álcoois formados e a quantidade de poliéter obtida varia com o tipo e a quantidade de catalisador, o solvente e a temperatura da reação. Estudos anteriores sugerem o emprego de ácido sulfúrico concentrado ${ }^{[9]}$ e dimetilbenzilamina ${ }^{[10]}$ como catalisadores de reações entre grupos epóxi e glicóis em sistemas com óxido de propileno ou óxido de estireno, mas a literatura, segundo nosso melhor conhecimento, carece de um estudo sistemático da modificação química de DGEBA com PEG.

Autor para correspondência: Sergio H. Pezzin, Centro de Ciências Tecnológicas, Universidade do Estado de Santa Catarina, Campus Universitário, 
Além de ser referenciada como catalisador da reação entre grupos epoxídicos e álcoois, a N,N-dimetilbenzilamina (DMBA) também é utilizada como acelerador da reação de cura da resina epoxídica com outras aminas ${ }^{[11]}$ e com anidridos ${ }^{[12]}$, podendo atuar como agente iniciador e co-agente da reação ${ }^{[13]}$.

Neste trabalho foi estudada a reação entre polietileno glicol e uma resina epoxídica a base de DGEBA, na presença de DMBA, sendo os produtos avaliados por espectroscopia no infravermelho (FTIR), espectroscopia de ressonância magnética nuclear (RMN) e viscosidade. Amostras curadas com um endurecedor à base de poliamina foram também submetidas a ensaios de tração e calorimetria exploratória diferencial (DSC).

\section{Experimental}

\section{Materiais}

Para a realização deste trabalho foram utilizados resina epoxídica Araldite GY 251, baseada em diglicidil éter de bisfenol A (DGEBA), e endurecedor Aradur HY 956, à base de poliamina alifática, ambos produzidos pela Hunstman. As propriedades da resina e do endurecedor são apresentadas na Tabela 1. N,N-dimetilbenzilamina e polietileno glicol com massa molar de 400 g.mol-1 $(\mathrm{PEG} 400)$ foram adquiridos da Sigma-Aldrich.

\section{Modificação química de DGEBA com PEG}

Com o objetivo de verificar a reação entre a resina epoxídica e PEG, $20 \mathrm{~g}$ de resina DGEBA (ca. 0,085 mol de grupos epoxídicos) foram misturadas a $20 \mathrm{~g}$ de PEG $(0,05 \mathrm{~mol})$ e $0,2 \mathrm{~g}$ de DMBA $\left(1,5 \times 10^{-3} \mathrm{~mol}\right)$. A razão DGEBA/PEG foi escolhida para garantir um leve excesso de grupos hidroxílicos do PEG $(0,10 \mathrm{~mol}$ de $-\mathrm{OH})$ em relação ao número de grupos epoxídicos $(0,085 \mathrm{~mol})$, enquanto a concentração de DMBA (ca. $0,5 \% \mathrm{~m} / \mathrm{m}$ ) foi selecionada com base no trabalho realizado por Shechter e colaboradores ${ }^{[10]}$.

A mistura foi transferida para um balão com três saídas para realizar a reação que foi conduzida em banho de glicerina e sob agitação magnética. A primeira amostra foi retirada após 1 hora sem aquecimento $\left(22^{\circ} \mathrm{C}\right)$. Na sequência, a temperatura do banho foi elevada a $100{ }^{\circ} \mathrm{C}$ e o sistema mantido sob refluxo por 10 horas. A cada hora uma pequena amostra da mistura foi retirada para análise de viscosidade, FTIR e RMN.

\section{Viscosidade}

As medidas de viscosidade foram realizadas em um viscosímetro cone-prato Brookfield CAP 2000. A rotação foi variada de 150 a $1500 \mathrm{rpm}$ enquanto a temperatura do prato foi mantida a $100{ }^{\circ} \mathrm{C}$.

Tabela 1. Propriedades da resina epoxídica e do endurecedor amínico.

\begin{tabular}{ccc}
\hline Propriedades & Araldite GY 251 & Aradur HY 956 \\
\hline Viscosidade a $25^{\circ} \mathrm{C}$ & $1350-1600 \mathrm{mPa} . \mathrm{s}$ & $450 \mathrm{mPa} . \mathrm{s}$ \\
Densidade a $25{ }^{\circ} \mathrm{C}$ & $1,14 \mathrm{~g} . \mathrm{cm}^{-3}$ & $1,02 \mathrm{~g} . \mathrm{cm}^{-3}$ \\
Teor epoxídico & $4,20-4,35 \mathrm{Eq} . \mathrm{kg}^{-1}$ & - \\
\hline
\end{tabular}

\section{Ressonância Magnética Nuclear (RMN) de ${ }^{1} \mathrm{H}$}

Os deslocamentos químicos de ${ }^{1} \mathrm{H}$ e ${ }^{13} \mathrm{C}(300 \mathrm{MHz})$ foram obtidos em equipamento da marca Varian Mercury Plus, com um magneto de 9,4 T. As análises foram realizadas usando $\mathrm{CDCl}_{3}$ como solvente e tetrametilsilano (TMS) como referência interna.

\section{Espectroscopia no infravermelho (FTIR)}

Espectros de FTIR foram obtidos em espectrômetro ThermoNicolet IR200. As amostras foram analisadas na faixa de leitura de 4000 a $600 \mathrm{~cm}^{-1}$ no módulo ATR, com resolução de $4 \mathrm{~cm}^{-1}$.

\section{Cura dos sistemas: DGEBA, DGEBA/PEG e DGEBA/PEG/DMBA}

Para verificar a influência da presença de DMBA na reação entre DGEBA e PEG durante o processo de cura, um experimento foi realizado adicionando-se endurecedor a base de poliamina alifática (20 pcr), polietileno glicol (10 pcr) e DMBA (0,65 pcr) a $100 \mathrm{~g} \mathrm{de}$ resina epóxi. A mistura foi homogeneizada manualmente (1 minuto) e vazada em moldes de silicone, para posterior cura em estufa por 20 horas a $70^{\circ} \mathrm{C}$.

\section{Ensaios mecânicos}

Os corpos de prova de tração foram ensaiados em uma máquina universal de ensaios mecânicos EMIC DL 30000 de acordo com a norma ASTM D638M-93, utilizando-se uma célula de carga de $1000 \mathrm{kgf}$ e velocidade de ensaio de $5 \mathrm{~mm} / \mathrm{min}$.

\section{Calorimetria Exploratória Diferencial (DSC)}

As análises de DSC nas amostras curadas foram realizadas em equipamento TA Instruments DSC Q20. As amostras foram aquecidas em duas corridas em temperatura de 0 até $250{ }^{\circ} \mathrm{C}$ com taxa de $10{ }^{\circ} \mathrm{C} / \mathrm{min}$ sob fluxo de nitrogênio a $50 \mathrm{~mL} / \mathrm{min}$.

\section{Resultados e Discussão}

Amostras retiradas durante e após a reação apresentaram alteração significativa na viscosidade, o que pode ser visualizado na Figura 2. O aumento da viscosidade sugere o aumento da massa molecular na nova estrutura formada, evidenciando a ocorrência da reação no sistema DGEBA-PEG na presença de DMBA. Pode-se perceber também que os sistemas apresentam um comportamento pseudo-plástico, que se acentua com o tempo de reação.

Poderia se considerar neste ponto a ocorrência de reações paralelas de polimerização do DGEBA durante o experimento a $100{ }^{\circ} \mathrm{C}$. Existem vários estudos na literatura sobre a homopolimerização e o "self-curing" do DGEBA, sendo muitas vezes contraditórios ${ }^{[13]}$. Reações de esterificação e homopolimerização podem ocorrer a temperaturas elevadas ou em condições não-estequiométricas. A esterificação ocorre com a abertura de anel do grupo epoxídico por grupos hidroxilas a temperaturas superiores a $150{ }^{\circ} \mathrm{C}^{[14]}$, com alta energia de ativação (ca. $100 \mathrm{~kJ} \cdot \mathrm{mol}^{-1}$ ), na etapa final da cura ou na presença de excesso de grupos epoxídicos ${ }^{[15]}$. No entanto, vários<smiles>CCC(C)(OCC1CO1)c1ccc(C(C)(C)c2ccc(OCC(O)COc3cccc(C(C)(C)c4cccc(OCC5CO5)c4)c3)cc2)cc1</smiles>

Figura 1. Diglicidil éter de bisfenol A (DGEBA). 
outros autores concluíram que reações paralelas são desprezíveis em sistemas estequiométricos e não-estequiométricos ${ }^{[16-18]}$. Recentemente $^{[13]}$, observou-se que para DGEBA puro aquecido de 25 a $300{ }^{\circ} \mathrm{C}$, um pico exotérmico muito pequeno é observado entre 180 e $300{ }^{\circ} \mathrm{C}$ (máximo em 250 a $5{ }^{\circ} \mathrm{C} / \mathrm{min}$ ), sendo que a partir de $300{ }^{\circ} \mathrm{C}$ a decomposição do DGEBA é o processo mais importante. Este mesmo estudo também abordou o uso de DMBA como "promotor" da reação de homopolimerização/ "self curing" do DGEBA, mostrando que a reação pode ocorrer em temperaturas superiores a $200{ }^{\circ} \mathrm{C}$ (máximo em 260 a $1,75^{\circ} \mathrm{C} / \mathrm{min}$ ).

Para confirmar a reação entre DGEBA e PEG na presença de DMBA, amostras do sistema DGEBA/PEG/DMBA foram retiradas do meio reacional após períodos de 1 a 7 horas a $100{ }^{\circ} \mathrm{C}$ e analisadas por espectroscopia de ressonância magnética nuclear de próton. As Figuras $3 \mathrm{a}$ e $3 \mathrm{~b}$ mostram os espectros das amostras tomadas após 1 e 7 horas de reação, respectivamente. Observam-se alguns picos bem característicos de resinas DGEBA. O pico em 1,63 ppm está relacionado com os prótons de grupos metila situados entre os dois anéis aromáticos da resina epóxi, enquanto que os picos agrupados na faixa entre 6,80 e 7,28 ppm são referentes aos prótons aromáticos. Os grupos glicidílicos terminais são responsáveis pelo aparecimento dos picos situados no intervalo de 2,6 a 4,3 $\mathrm{ppm}^{[19]}$, enquanto o forte

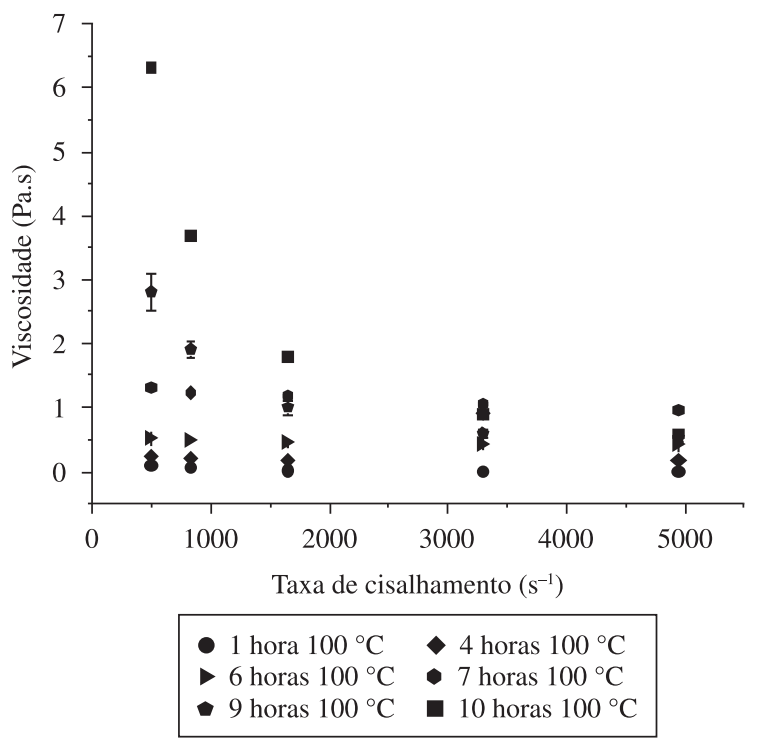

Figura 2. Viscosidade do sistema DGEBA-PEG após diferentes tempos de reação em função da taxa de cisalhamento.

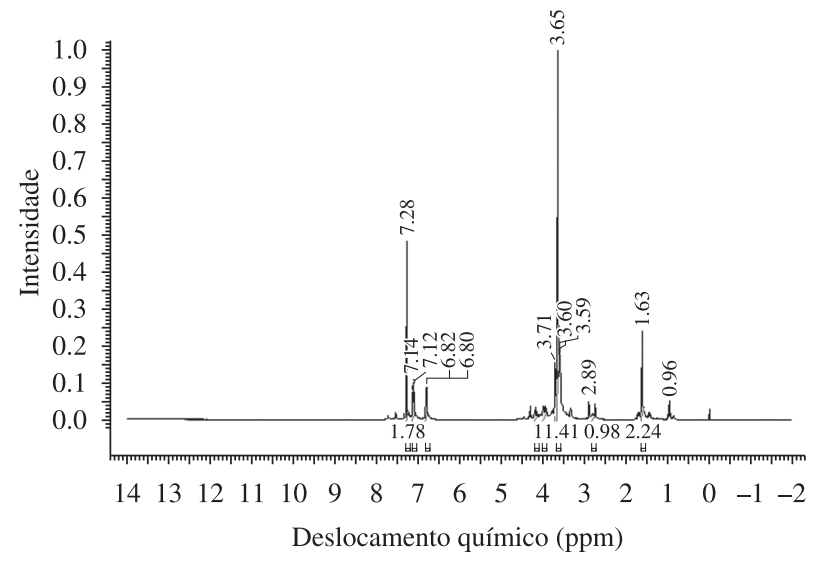

(a) pico ao redor de 3,65 ppm está relacionado aos grupos metilênicos $\left(-\mathrm{CH}_{2}-\right)$ do $\mathrm{PEG}^{[20,21]}$. O pico em 7,28 ppm é referente ao próton do clorofórmio, usado como solvente.

A existência de ligação covalente entre DGEBA e PEG é evidente pelo aparecimento de um multiplete de baixa intensidade ao redor de 4,2 ppm, que representa os prótons metilênicos das unidades terminais aciladas $\left(-\mathrm{CH}_{2}-\mathrm{O}-\mathrm{CO}-\right)$ das cadeias de $\mathrm{PEG}^{[21]}$. Uma outra alteração importante nos espectros de $\mathrm{RMN}-{ }^{1} \mathrm{H}$ com o tempo de reação é o deslocamento do dublete referente aos grupos glicidílicos da resina epóxi, em 2,89 ppm. Este pico, presente no espectro do sistema após 1 hora a $100{ }^{\circ} \mathrm{C}$ (Figura 3a), muda para um singlete em 2,67 ppm (Figura 3b) após 7 horas de reação a $100{ }^{\circ} \mathrm{C}$, o que está provavelmente relacionado à formação de grupos $-\mathrm{OH}$ a partir da quebra dos grupos glicidila.

Amostras de DGEBA/PEG/DMBA retiradas com 1 hora a $22^{\circ} \mathrm{C}$ e 7 horas a $100{ }^{\circ} \mathrm{C}$ também foram analisadas por Espectroscopia no Infravermelho (FTIR), Figura 4. Na Figura 4b, ampliada na região entre 750 e $1000 \mathrm{~cm}^{-1}$, observa-se o diminuição da intensidade da banda em $914 \mathrm{~cm}^{-1}$ que é característica de grupos epoxídicos ${ }^{[22,23]}$, indicando que houve o consumo de grupos epoxídicos no sistema DGEBA/PEG/DMBA após 7 horas a $100{ }^{\circ} \mathrm{C}$. Nas condições estudadas, este consumo está provavelmente relacionado à reação entre grupos epoxídicos do DGEBA e grupos hidroxilas do PEG na presença de DMBA. Em $3440 \mathrm{~cm}^{-1}$ na Figura 4a é observado um pico bem amplo referente à vibração (estiramento) do grupo $-\mathrm{OH}$ do $\mathrm{PEG}^{[24]}$. Shechter e colaboradores ${ }^{[10]}$ mencionam que na reação entre glicidil éter e álcool ocorre a formação de grupos hidroxilas que também podem reagir na sequência com outros grupos epoxídicos até que todos esses reagentes envolvidos sejam consumidos, sendo a velocidade da reação relacionada diretamente a quantidade de hidroxilas presentes, presença de catalisadores (por exemplo, DMBA) e temperaturas acima de $100{ }^{\circ} \mathrm{C}$.

Em relação ao papel da DMBA, este fica claro quando consideramos o comportamento do sistema sem a sua presença, já que os espectros obtidos após 1 hora e após 8 horas a $100{ }^{\circ} \mathrm{C}$ são idênticos na ausência de DMBA (Figura 5) e não indicam o desaparecimento do pico a $914 \mathrm{~cm}^{-1}$, referente aos grupos epoxídicos.

Os resultados dos ensaios de tração dos sistemas curados, apresentados na Tabela 2, mostram uma redução na tensão máxima e no módulo elástico e um aumento na deformação para os sistemas DGEBA/PEG, quando comparados com a resina pura, o que pode ser atribuído a um efeito plastificante do $\mathrm{PEG}^{[25,26]}$. O sistema DGEBA/PEG/DMBA apresentou uma redução mais significativa nas propriedades de tensão máxima e módulo de elasticidade e um aumento considerável na deformação em relação à mistura epóxi/ PEG. Essas alterações observadas nas propriedades mecânicas

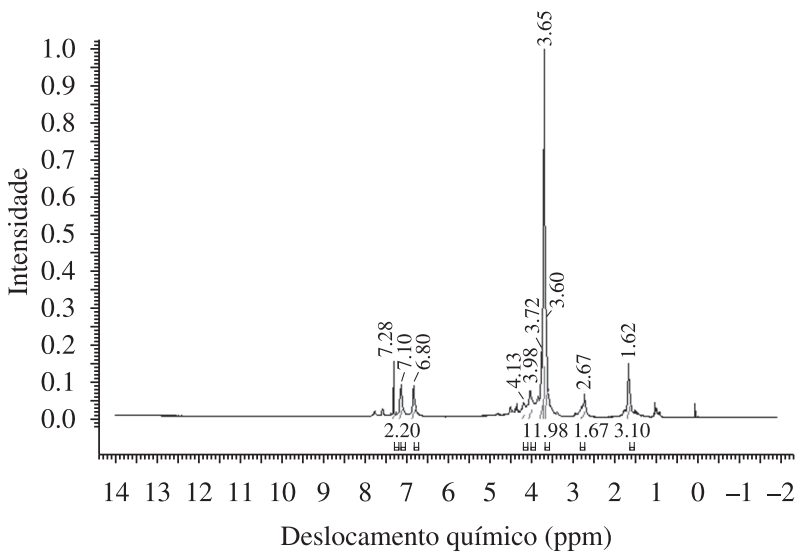

(b)

Figura 3. Espectros de $\mathrm{RMN}-{ }^{1} \mathrm{H}$ de sistemas DGEBA/PEG/DMBA: a) 1 hora/ $100{ }^{\circ} \mathrm{C}$ e b) 7 horas $/ 100{ }^{\circ} \mathrm{C}$. 


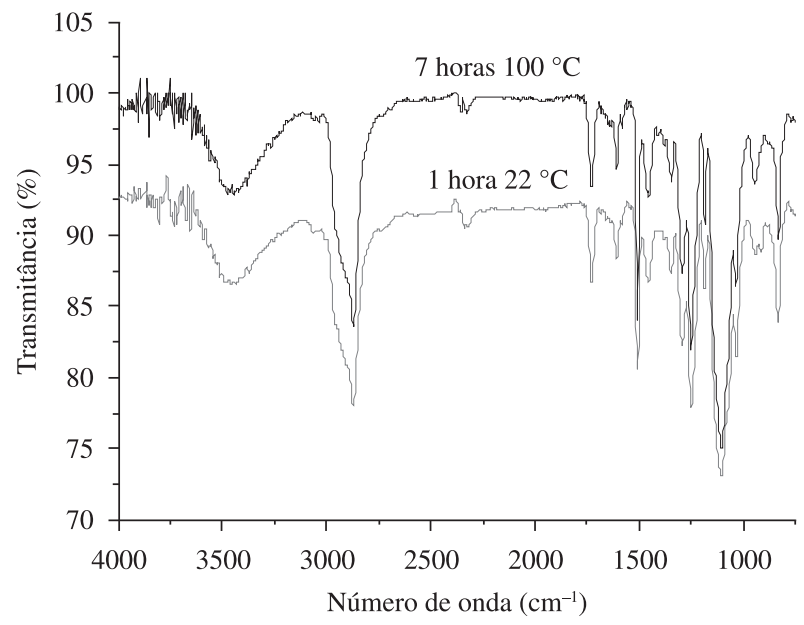

(a)

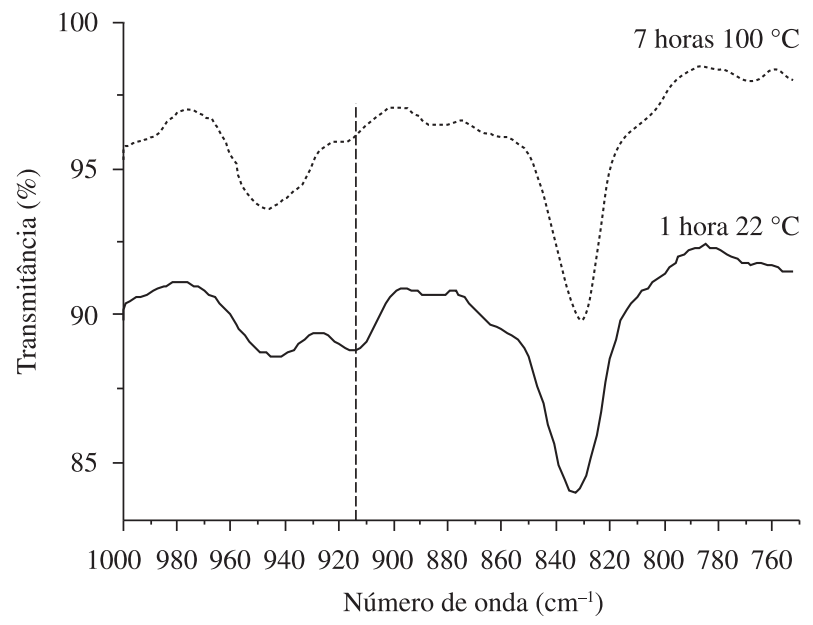

(b)

Figura 4. Espectros de FTIR de sistemas DGEBA/PEG/DMBA após a) 1 hora a $22{ }^{\circ} \mathrm{C}$ e b) 7 horas a $100{ }^{\circ} \mathrm{C}$.

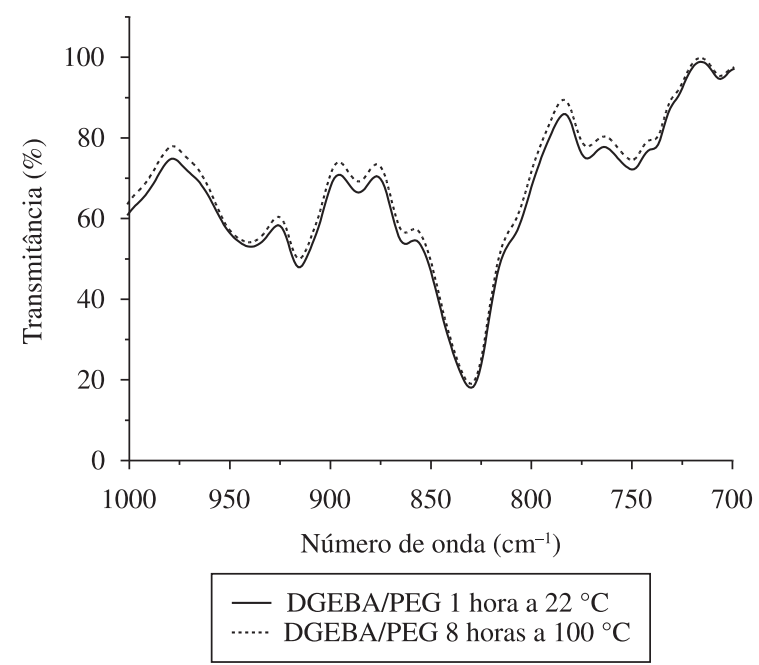

Figura 5. Espectros de FTIR do sistema DGEBA/PEG, sem adição de DMBA.

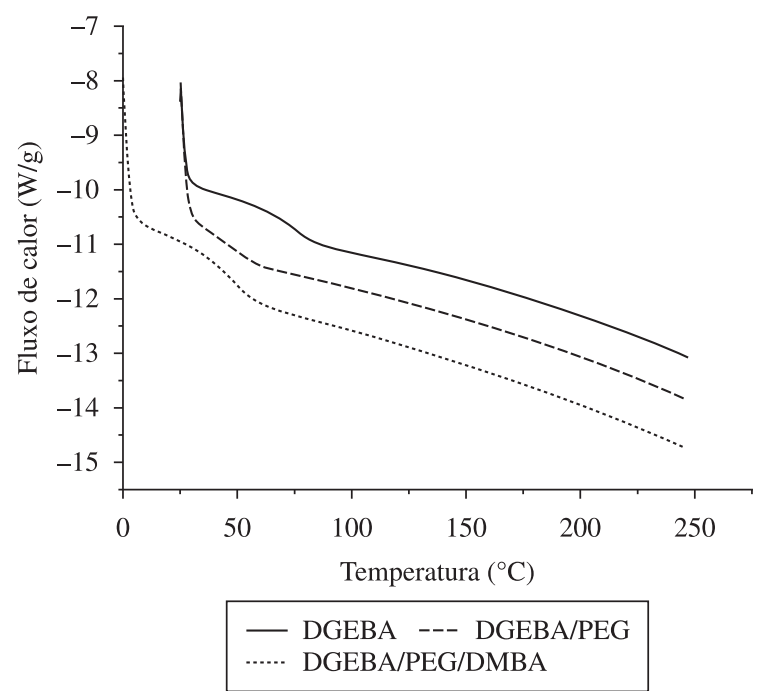

Figura 6. Curvas de DSC de sistemas DGEBA, DGEBA/PEG e DGEBA/ PEG/DMBA
Tabela 2. Propriedades mecânicas de sistemas DGEBA, DGEBA/PEG e DGEBA/PEG/DMBA após cura.

\begin{tabular}{cccc}
\hline Sistema & $\begin{array}{c}\text { Tensão } \\
\text { máxima } \\
(\mathbf{M P a})\end{array}$ & $\begin{array}{c}\text { Deformação } \\
(\mathbf{\%})\end{array}$ & $\begin{array}{c}\text { Módulo } \\
\text { elástico } \\
(\mathbf{G P a})\end{array}$ \\
\hline DGEBA & $41,6 \pm 1,2$ & $3,2 \pm 0,1$ & $2,2 \pm 0,1$ \\
DGEBA/PEG & $18,3 \pm 0,4$ & $4,4 \pm 0,1$ & $1,0 \pm 0,1$ \\
DGEBA/PEG/DMBA & $14,8 \pm 0,6$ & $14,4 \pm 1,7$ & $0,7 \pm 0,2$ \\
\hline
\end{tabular}

Tabela 3. Temperaturas de transição vítrea (Tg), obtidas por DSC, de sistemas DGEBA, DGEBA/PEG e DGEBA/PEG/DMBA, após cura.

\begin{tabular}{cc}
\hline Sistema & $\mathbf{T g}\left({ }^{\circ} \mathbf{C}\right)$ \\
\hline DGEBA & 73 \\
DGEBA/PEG & 46 \\
DGEBA/PEG/DMBA & 45 \\
\hline
\end{tabular}

podem estar relacionadas com a incorporação de segmentos flexíveis de PEG400 entre os segmentos advindos da resina epóxi. $\mathrm{Na}$ presença de DMBA obtém-se novo material, muito mais flexível, apresentando módulos mais baixos e maiores valores de deformação na ruptura.

As curvas dos ensaios de calorimetria exploratória diferencial (DSC) são mostrados na Figura 6. Os resultados, sumarizados na Tabela 3, mostram uma diminuição significativa da temperatura de transição vítrea (Tg) nos sistemas epóxi/PEG e epóxi/PEG/DMBA quando comparados com a resina epóxi pura. Esta redução na $\mathrm{Tg}$ pode explicar o considerável aumento da flexibilidade apresentado por estes sistemas nos ensaios de tração.

\section{Conclusões}

As análises de viscosimetria, FTIR e RMN $\left({ }^{1} \mathrm{H}\right)$ confirmaram a ocorrência de uma reação entre grupos epóxi do DGEBA e grupos hidroxila do PEG na presença de DMBA, a $100{ }^{\circ} \mathrm{C}$.

Os ensaios mecânicos indicam que os novos materiais apresentam módulo de elasticidade menor que o da resina pura, bem como uma menor tensão máxima de ruptura. Entretanto, as deformações dos novos materiais apresentaram um grande incremento em relação à resina pura. As análises de DSC indicaram redução significativa da $\mathrm{Tg}$ em sistemas DGEBA/PEG em relação à resina epoxídica (DGEBA), corroborando os resultados obtidos nos ensaios mecânicos. 


\section{Agradecimentos}

Os autores agradecem ao CNPq (Proc. 479884/2007-2), AEB-Uniespaço e CAPES-PROCAD, pela ajuda financeira.

\section{Referências Bibliográficas}

1. Chen, H.; Jacobs, O.; Wu, W.; Rudiger, G. \& Schadel, B. - Polym. Test., 26, p.351 (2007).

2. Thomas, R.; Durix, S.; Sinture, C.; Omonov, T.; Goossens, S.; Groeninckx, G.; Moldenaers, P. \& Thomas, S. - Polymer, 48, p.1695 (2007).

3. Brydson, J. - "Plastics materials", Butterworths, London (1999).

4. Ooi, S. K.; Cook, W. D.; Simin, G. P. \& Such, C. H. - Polymer, 41, p.3639 (2000).

5. McGarry, F. J. \& Arends, C. B. - "Polymer toughening", Marcel Dekker, New York (1996).

6. Gojny, F. H.; Wichmann, M. H.; Fiedler, B. \& Schulte, K. - Comp. Sci. Technol., 65, p.2300 (2005).

7. Wang, Y.; Xiong, H.; Gao, Y. \& Li, H. - J. Mater. Sci., 43, p.5609 (2008).

8. Tanaka, Y.; Bauer, R. S. - "Epoxy resins - Chemistry and technology", Marcel Dekker, New York (1988).

9. Chitwood, H. C. \& Freure, B. T. - J. Am. Chem. Soc., 68, p.680 (1946).

10. Shechter, L.; Wynstra, J. \& Kurkjy, R. P. - Ind. Eng. Chem., 49, p.1107 (1957).

11. Ståhlbom, B.; Åkesson, B. \& Jönsson, B. - Int. Arch. Occup. Environ. Health, 70, p.393 (1997).
12. Montserrat, S.; Flaqué, C.; Calafell, M.; Andreu, G. \& Málek, J. Thermochim. Acta, 269/270, p.213 (1995).

13. Sbirrazzuoli, N.; Mititelu-Mija, A.; Vincent, L. \& Alzina, C. Thermochim. Acta, 447, p.167 (2006).

14. Chiao, L. - Macromolecules, 23, p.1286 (1990).

15. Mijovic, J. \& Wijaya, J. - Polymer, 35, p.2683 (1994).

16. Swier, S. \& van Mele, B. - Termochim. Acta, 411, p.149 (2004).

17. Xu, L. et al. - Ind. Eng. Chem. Res., 35, p.963 (1996).

18. Finzel, M. C. et al. - J. Polym. Sci., Part A: Polym. Chem., 33, p.673 (1995).

19. Garcia, F. G. \& Soares, B. G. - Polym. Test., 22, p.51 (2003).

20. Heald, C. R.; Stolnik, S.; Kujawinski, K. S.; Matteis, D.; Garnett, M. C.; Illum, L.; Davis, S. S.; Purkiss, S. C.; Barlow, R. J. \& Gellert, P. R. - Langmuir, 18, p.3669 (2002).

21. Ren, J.; Hong, H.; Ren, T. \& Teng, X. - React. Funct. Polym., 66, p.944 (2006).

22. Loos, M. R.; Coelho, L. A. F.; Pezzin, S. H. \& Amico, S. C. - Polímeros, 18, p.76 (2008).

23. Lau, K.; Gu, C.; Hui, D. - Composites: Part B, 37, p.425 (2006).

24. Niu, L.; Luo, Y. \& Li, Z. - Sens. Actuat. B., 126, p.361 (2007).

25. Samanta, B. C.; Maity, T.; Kar, S. \& Banthia, A. K. - Pigm. Resin Technol., 4, p.34 (2005).

26. Kundu, J.; Patra, C. \& Kundu, S. C. - Mat. Sci. Eng. C., 28, p.1376 (2008).

Enviado: 29/10/09

Reenviado: 11/08/10

Aceito: $17 / 08 / 10$

DOI: 10.1590/S0104-14282011005000009 